\title{
Topographic effects on spatial pattern of surface air temperature in complex mountain environment
}

\author{
Ranhao Sun ${ }^{1} \cdot$ Baiping Zhang ${ }^{2}$
}

Received: 16 January 2015/ Accepted: 11 February 2016/Published online: 2 April 2016

(C) Springer-Verlag Berlin Heidelberg 2016

\begin{abstract}
Understanding topographic effects on surface air temperature (SAT) is essential in developing an accurate prediction model in complex mountain environment. A nonlinear topographic regression model is developed to predict the spatial SAT pattern using latitude, elevation, slope, and aspect. Monthly SAT data have been collected from 14 meteorological stations between 1960 and 2010 in the Daqing Mountains of China. Topographic data are acquired from a $30 \mathrm{~m}$ resolution digital elevation model of the study region. Results show that: (1) the SAT models are able to explain $89-95.8 \%$ of the spatial variation in different months. Elevation has the strongest effect on the SAT variation in all months (average $84.78 \%$ ). (2) The combined contribution of slope and aspect to SAT variations is larger (average $9.14 \%$ ) than that of latitude (average $6.07 \%$ ). (3) The combined effect of slope and aspect on SAT variations is higher in winter than in summer. The introduction of slope and aspect optimizes the SAT modeling in different months. In further studies, the accuracy of SAT model might be improved by introducing alternative topographic factors to capture the vegetation and weather condition.
\end{abstract}

Ranhao Sun

rhsun@rcees.ac.cn

1 State Key Laboratory of Urban and Regional Ecology, Research Center for Eco-Environmental Sciences, Chinese Academy of Sciences, Beijing 100085, China

2 State Key Laboratory of Resource and Environment Information System, Institute of Geographic Sciences and Natural Resources Research, Chinese Academy of Sciences, Beijing 100101, China
Keywords Surface air temperature $\cdot$ Multivariate regression · Topographic effect · Mapping · Interpolation · China

\section{Introduction}

The spatial distribution of surface air temperature (SAT) is an important basis for understanding the phenomena and processes in many disciplines, including geography, ecology, hydrology, agriculture, and environment management. The SAT is generally measured at very few stations, especially in complex mountain areas (Bolstad et al. 1998). Therefore, it is necessary to use interpolation techniques to predict the spatial pattern of SAT at a large scale. Researchers made great efforts to map the SAT to meet the requirements of different disciplines. Early studies described the spatial pattern of SAT using temperature isolines (Huang 1986) and meteorological station data (Fang 1992; Wang 1996). Later research placed efforts on developing spatial interpolation methods using limited station data, such as the inverse distance weighted method, spline method, trends method, and kriging method. Existing interpolation methods are mainly based on the distance of nearby meteorological stations and values of measured temperature (Beek et al. 1992; Lookingbill and Urban 2003).

Topographic factors in different spatial scales can affect the solar radiation and air movement that are responsible for the SAT variations (Ninyerola et al. 2000). In the macro-scale area, latitude is a direct factor influencing the distribution of solar radiation. Longitude represents the distance from the nearest ocean and determines the atmosphere circulation (Wallace et al. 2010). In the meso-scale area, mountains are topographic barriers to the movement and flow of air. The SAT decreases along the increasing 
elevation because of the adiabatic cooling (Dodson and Marks 1997). In the local-scale area, slope and aspect are responsible for the redistribution of solar radiation on different terrains. Taking advantage of the geographical information system (GIS) technology and digital elevation model (DEM), some interpolation methods have been improved by adding the effects of limited topographic factors into existing computer algorithms, such as the cokriging method. Other interpolation methods, such as the Australian National University spline model (ANUSPLIN) are modified using thin plate smoothing splines (McKenney et al. 2006). However, existing interpolation procedures are seldom focused on the interrelationship among different topographic factors.

Multivariate regression is a general model used to investigate the relationship among different factors. Regression models have been used to integrate multiple topographic factors in SAT models (Daly et al. 2002; Goodale et al. 1998; Liu and Zou 2006). For example, the parameter-elevation regressions on independent slopes model (PRISM) used point data to produce continuous grid estimates of climatic parameters at a large scale (Daly et al. 1994, 2002). The mountain climate simulator (MTCLIM) was used to predict the SAT according to the base temperatures and a temperature lapse rate in mountain areas (Li et al. 2001; Lo et al. 2011; Running et al. 1987). Recent studies have made progresses pertaining to the multivariate colinearity effect of different factors in large-scale areas (Kattel and Yao 2013; Kattel et al. 2015). In most studies, latitude, longitude, and elevation were preferred factors when topography was correlated with the SAT (Brown and Comrie 2002; Goodale et al. 1998; Lookingbill and Urban 2003; Ollinger et al. 1995). The effect of slope and aspect on the SAT distribution has been emphasized in recent years (Weng and Luo 1990; Zhao et al. 2005). The SAT models were developed by different structures in the northern and southern aspects of a mountain (Liu and Zou 2006; Xu et al. 2006; Zhao et al. 2005).

The relationship among different topographic factors is important in term of developing a SAT regression model. Many multivariate regressions were developed by the oneterm polynomial with the overlay of different topographic effects (Ninyerola et al. 2000; Lookingbill and Urban 2003; Liu and Zou 2006). These simple models were easy to implement in different areas. The relationship among topographic factors was weakened and even ignored in these models. Some research developed sophisticated regression models to capture the topographic information with quadratic (Bolstad et al. 1998; Goodale et al. 1998) or cubic polynomials (Sun et al. 2008). However, the model structures lacked sufficient supports from meteorological processes. These models provided even less information about the relative contribution of different topographic effects. Although some studies showed that topographic effects on the SAT do not occur separately and always work together (Zhang et al. 2002), relatively few results were available to quantify the combined effect of slope and aspect in a SAT model. We also need to know the relative contribution of different topographic factors to SAT variations for different months.

The combined effect of slope and aspect is assumed to impact the SAT because local topographic factors are significant contributors to the solar radiation accepted by the land surface (Kumar et al. 1997; Goodale et al. 1998). A multivariate regression model is developed to quantify topographic effects in macro-, meso-, and local-scale areas. This study aims to: (1) quantify the relative contribution of topographic variables to the SAT variation; and (2) identify the change of topographic effects in different months.

\section{Materials and methods}

\section{Study area}

The study area (Daqing Mountains) includes Mount Daqing and its surrounding mountainous regions. It is located at $40^{\circ} 10^{\prime}-42^{\circ} 00^{\prime} \mathrm{N}$ and $100^{\circ} 10^{\prime}-112^{\circ} 10^{\prime} \mathrm{E}$, covering $9336 \mathrm{~km}^{2}$ and ranging in elevation from 900 to $2300 \mathrm{~m}$ (Fig. 1). The climate of the Daqing Mountains is severely affected by the Mongolian high-pressure system and the westerly stream. The SAT decreases from south to north in the study area. This region is characterized by a warm-moist summer and cold-dry winter (Liu et al. 2004). The annual precipitation is about $345 \mathrm{~mm}$, and more than $78 \%$ of the annual precipitation occurs within 4 months, from June to September (Sun et al. 2008). The Daqing Mountains are the transition terrains between the Inner Mongolian Plateau and the Hetao Plain. The topographic features change dramatically within only a few kilometers of planimetric distance. The complex topographic features enforce the spatial differentiation of precipitation and temperature. The Daqing Mountains cross several significant geographical boundaries in China. The study region forms the dividing zone between the warmtemperate and temperate climate and lies between the semiarid and arid zones in China (Liu 1992). Therefore, as a climatic and geographical transition zone, the study area provides complex topographic characteristics to test and verify the SAT model.

\section{Data collection}

The SAT is measured using a mercury thermometer, which is installed in an instrument shelter at $1.5 \mathrm{~m}$ above ground level. The monthly SAT is averaged from the daily temperatures that are gathered each month; each daily 
Fig. 1 Study area and spatial distribution of stations in the Daqing Mountains

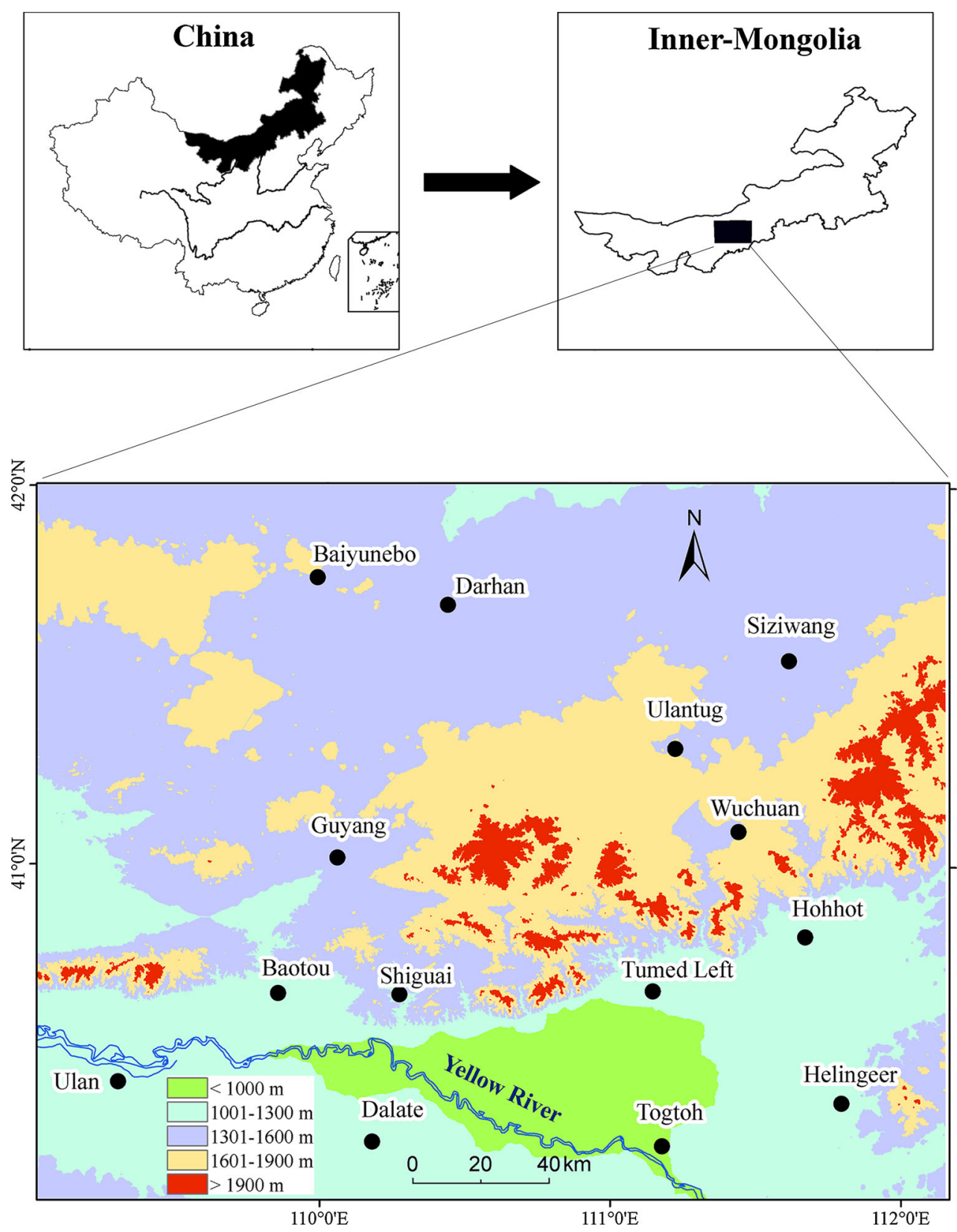

temperature is actually the mean of four records in Chinese time at 2 a.m., 8 a.m., 2 p.m., and 8 p.m. The monthly SAT is collected from the China Meteorological Administration (CMA). Any potential errors in the SAT observations have been corrected by the CMA, utilizing several quality control (QC) procedures (Tao et al. 1991). The QC of raw data includes a gross error check, basic time checks, and internal consistency checks. These QC procedures eliminate errors of sensors, measurement errors (systematic or random), errors inherent in measurement procedures and methods. Before they are distributed through the China Meteorological Data Sharing Service System, the SAT data deal with comprehensive checking of temporal and internal consistency, evaluation of biases and long-term drifts of sensors and modules, malfunction of sensors, etc.

We selected 14 stations of SAT data with an observation length large than 20 years between 1960 and 2010 (Table 1). After reviewing related studies, we found that latitude, longitude, elevation, slope, and aspect were the most cited factors in SAT modeling (Brown and Comrie 2002; Liu and Zou 2006; Ninyerola et al. 2000; Xu et al. 2006; Zhang et al. 2002; Zhao et al. 2005). Topographic factors were derived from the 1:250,000 national topographical data sets. We have mapped monthly mean precipitation from 1955 to 1990 in this region (Sun et al. 2008, 2011). The monthly mean precipitation data were used to 


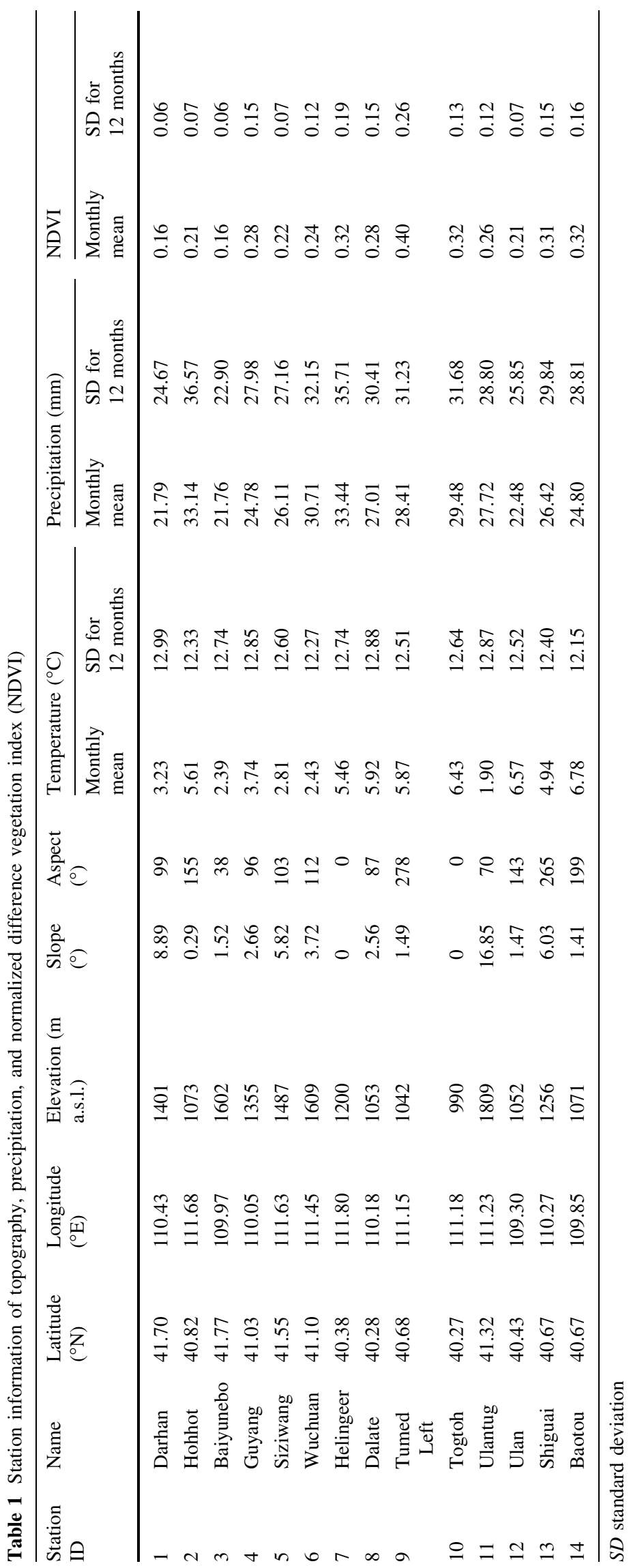


represent the impact of weather conditions on SAT variations. The normalized difference vegetation index (NDVI) was a useful indicator to quantify the vegetation condition (Miao et al. 2015). The monthly mean NDVI was downloaded from the official NASA website with 1-km spatial resolution in 2010 (http://modis.gsfc.nasa.gov/). Finally, we obtained dependent and independent variables including monthly mean SAT, monthly mean precipitation, monthly mean NDVI, latitude, longitude, elevation, slope, and aspect. The significance of Shapiro-Wilk statistical tests showed that the data series were normally distributed in 12 months.

\section{Multivariate regression model}

Pearson correlation coefficients were calculated among the dependent variable (monthly SAT) and independent variables (longitude, latitude, elevation, slope, aspect, precipitation, and NDVI) (Table 2). The results showed that impacts of precipitation and NDVI on the SAT varied in different months. Their relationships were too complex to predict the spatial pattern of SAT. The longitude was not selected because it had no significant correlation with the SAT. Finally, four topographic predictors were included in the SAT model including latitude, elevation, slope, and aspect.

Four regression models were compared by selecting different topographic predictors. Model 1 was developed with elevation as the sole predictor (Eq. 1). Model 2 was developed with latitude and elevation as the predictors (Eq. 2). Model 3 was developed with latitude, elevation, slope, and aspect all acting as predictors (Eq. 3). These models did not consider the combined effect of slope and aspect on the SAT. They were developed according to the linear combination of topographic factors.

$T=b_{0}+b_{2} H$
$T=b_{0}+b_{1} Y+b_{2} H$

$T=b_{0}+b_{1} Y+b_{2} H+b_{3} \beta+b_{4} \alpha$

where $T$ is the predicted SAT $\left({ }^{\circ} \mathrm{C}\right) ; H$ is the elevation above sea level $(\mathrm{m}) ; Y$ is the projected coordinate $(\mathrm{km}) ; b_{0}$ is constant; $b_{1}, \ldots, b_{4}$ are the coefficients obtained for each independent variable; $\beta$ is the slope (degree); and $\alpha$ is the aspect (degree) $-0^{\circ}$ to the north, increasing clockwise, and $180^{\circ}$ to the south.

The solar radiation accepted by land surface varied according to the slope and aspect of terrains. The combined effect of slope and aspect can be estimated by the calculation of potential solar radiation. The terrain-induced SAT variation $(\Delta T)$ was quantified using the following equation (Kumar et al. 1997).

$\Delta T=k \times I_{p} / I_{s}=k \times \cos i$

where $k$ is a constant; $I_{p}$ is the solar radiation on a tilted surface; $I_{s}$ is the solar radiation on a surface normal to the sun's rays; $i$ is the angle between the normal to the surface and the direction to the sun. According to related references (Dozier and Frew 1990; Kumar et al. 1997),

$\cos i=\sin \delta \cos \beta-\cos Y \sin \beta \cos \alpha+\cos \delta \cos \varepsilon$

$(\cos Y \cos \beta+\sin Y \sin \beta \cos \alpha)+\cos \delta \sin \beta \sin \alpha \sin \varepsilon$

where $\delta$ is the solar declination (degree); $\varepsilon$ is the solar hour angle (degree). Because $\delta$ equaled $\varepsilon$ in a grid, $\Delta T$ can be described as,

$\Delta T=k_{1} \cos \beta+k_{2} \sin \beta \cos \alpha+k_{3} \sin \beta \sin \alpha+k_{4}$

where $k_{1}, \ldots, k_{4}$ represent constants. Using $b_{3}, b_{4}$, and $b_{5}$ to replace $k_{1}, k_{2}$, and $k_{3}$, the nonlinear topographic regression on surface air temperature (NTRSAT) was defined as (Model 4),

$$
\begin{aligned}
T= & b_{0}+b_{1} Y+b_{2} H+b_{3} \cos \beta+b_{4} \sin \beta \cos \alpha \\
& +b_{5} \sin \beta \sin \alpha
\end{aligned}
$$

Table 2 Correlation coefficients between monthly temperature and predictors of topography, precipitation, and normalized difference vegetation index (NDVI)

\begin{tabular}{llllllllllllll}
\hline & Jan & Feb & Mar & Apr & May & Jun & Jul & Aug & Sep & Oct & Nov & Dec \\
\hline Latitude & $-0.79^{* *}$ & $-0.85^{* *}$ & $-0.88^{* *}$ & $-0.87^{* *}$ & $-0.89^{* *}$ & $-0.84^{* *}$ & $-0.81^{* *}$ & $-0.83^{* *}$ & $-0.84^{* *}$ & $-0.88^{* *}$ & $-0.88^{* *}$ & $-0.77^{* *}$ \\
Longitude & -0.27 & -0.21 & -0.16 & -0.20 & -0.23 & -0.31 & -0.33 & -0.25 & -0.26 & -0.13 & -0.11 & -0.30 \\
Elevation & $-0.90^{* *}$ & $-0.94^{* *}$ & $-0.97^{* *}$ & $-0.97^{* *}$ & $-0.96^{* *}$ & $-0.96^{* *}$ & $-0.95^{* *}$ & $-0.97^{* *}$ & $-0.98^{* *}$ & $-0.97^{* *}$ & $-0.95^{* *}$ & $-0.92^{* *}$ \\
Slope & $-0.64^{*}$ & $-0.67^{* *}$ & $-0.66^{*}$ & $-0.61^{*}$ & $-0.60^{*}$ & $-0.60^{*}$ & $-0.60^{*}$ & $-0.62^{*}$ & $-0.65^{*}$ & $-0.66^{* *}$ & $-0.63^{*}$ & $-0.67^{* *}$ \\
Aspect & 0.41 & 0.34 & 0.31 & 0.23 & 0.24 & 0.21 & 0.18 & 0.22 & 0.24 & 0.24 & 0.33 & 0.36 \\
Precipitation & $-0.55^{*}$ & 0.18 & $0.70^{* *}$ & -0.01 & -0.05 & -0.35 & 0.20 & 0.39 & 0.37 & -0.01 & -0.17 & $-0.82^{* *}$ \\
NDVI & $0.77^{* *}$ & 0.42 & 0.30 & 0.26 & 0.32 & $0.59^{*}$ & 0.47 & 0.32 & 0.28 & $0.54^{*}$ & 0.34 & 0.16 \\
\hline
\end{tabular}

Significance at the level of $0.05(* *)$ and $0.1(*)$ 
The coefficients of monthly SAT models were calculated by the SPSS software. The $t$ statistic is a statistical hypothesis testing which indicates the probability if the true correlation between dependent and independent variables is zero. The Tolerance statistic is used to measure the strength of the linear relationship between different independent variables. The Durbin-Watson (DW) value is a test statistic to detect the presence of autocorrelation in residuals. A DW value of 2 indicates that there appears to be no autocorrelation (King 1981).

\section{Geo-statistical interpolation method}

Co-kriging is a multivariate geo-statistical interpolation that uses a secondary variable to improve the prediction accuracy (Park 2011). The co-kriging interpolation was used to compare the predicted SAT with the NTRSAT model. In this study, co-kriging was implemented with two datasets including the station elevation and the SAT data. Different types of semi-variogram models were analyzed to obtain the best fit or goodness model. An exponential semivariogram model was selected because it fits the empirical semi-variogram cloud well. The lag size was tried and calibrated interactively. The experimental semi-variogram, after flattening out for distances above $20 \mathrm{~km}$, showed a flat curve as distances increased. Thus, a search neighborhood of $20 \mathrm{~km}$ was used for SAT modeling when the co-kriging was applied. The number of lags in this study was defined as 10 . The search neighborhood was defined as an ellipse in four sections with a 45 degree offset. The minimum number of samples used for estimation was taken as 2 , excluding the value of the estimation location.

\section{Model evaluation method}

Partial regression analysis was used to estimate how much variation of the SAT can be attributed exclusively to specific topographic factors (Lattin et al. 2003). The $F$ value of partial regression analysis measured the relative contribution of topographic factors. The determination coefficient represented the proportion of SAT variations explained by the regression model.

$$
\begin{aligned}
F & =\frac{\mathrm{SSR}_{j} / d f_{j}}{\mathrm{SSE} / d f}=\frac{\left(\mathrm{SSE}_{r}-\mathrm{SSE}\right) /\left(d f_{r}-d f\right)}{\mathrm{SSE} / d f} \\
& =\frac{\left(R^{2}-R_{r}^{2}\right) /\left(d f_{r}-d f\right)}{\left(1-R^{2}\right) / d f}
\end{aligned}
$$

where $R^{2}$ is the determination coefficient; $\mathrm{SSR}_{\mathrm{j}}$ is the residual sum of squares explained by $X_{j}$, which equals the difference between the explained sum of squares for models with (SSE) and without $X_{j}(\mathrm{SSEr})$; and $d f_{j}, d f_{r}$, and $d f$ represent the degrees of freedom for variable $X_{j}$, the restrictive model (the model without $X_{j}$ ), and the overall model (the model with all variables), respectively.

A Jackknifing method was used to estimate the precision of regression models. This method repeated a procedure using a single observation from the original sample as the validation data, and treated the remaining observations as the training data (Efron 1982; Shao and Tu 1995). The mean absolute error (MAE) described the error of predicted versus measured air temperature, whereas the root mean squared error (RMSE) measured the spread of the data around the regression line.

$$
\begin{aligned}
\operatorname{MAE}_{m} & =\frac{1}{n} \sum_{i=1}^{n}\left|T_{i}-M_{i}\right| \\
\mathrm{RMSE}_{m} & =\sqrt{\frac{1}{n} \sum_{i=1}^{n}\left(T_{i}-M_{i}\right)^{2}}
\end{aligned}
$$

where $T_{i}$ is the predicted value of the monthly mean temperature; $M_{i}$ is the measured value of the monthly mean temperature; $m$ is the month, and $n$ is the number of stations.

\section{Results}

\section{Statistics of regression model}

The mean monthly SAT of stations was $4.58^{\circ} \mathrm{C}$, with a range from 1.9 to $6.78{ }^{\circ} \mathrm{C}$. The monthly precipitation ranged from 21.76 to $33.44 \mathrm{~mm}$ (average $27 \mathrm{~mm}$ ). The monthly NDVI ranged from 0.16 to 0.4 (average 0.26 ). The elevation of stations ranged from 990 to $1809 \mathrm{~m}$ (average $1286 \mathrm{~m}$ ). Table 3 shows the amount proportion of the stations and topographic predictors.

The coefficients of the NTRSAT model were calculated in different months (Table 4). The Tolerance values of all independent variables were larger than 0.1 , indicating that there was little evidence of multicollinearity among independent variables. The determination coefficients showed that the models can account for $89-95.8 \%$ of the SAT variation.

The terms of $b_{1}$ represented the impact of latitude on the SAT in different months. They were positive values in June through September and December through February, whereas the other months reported negative values. The terms of $b_{2}$ showed temperature lapse rates for 12 months. The negative values of $b_{2}$ indicated that the SAT decreased with increasing elevation. The temperature lapse rates ranged from -5.2 (October) to $-8.2{ }^{\circ} \mathrm{C} \mathrm{km}^{-1}$ (February), with an average of $-7{ }^{\circ} \mathrm{C} \mathrm{km}^{-1}$ for 12 months. The terms of $b_{3}$ represented the impact of slope on the SAT, whereas the terms of $b_{4}$ and $b_{5}$ represented the combined impacts of 
Table 3 Amount proportion of station (POS) and area proportion of topographic factors (POT) in different elevation, slope, and aspect

\begin{tabular}{|c|c|c|c|c|c|c|c|c|}
\hline \multicolumn{3}{|l|}{ Elevation } & \multicolumn{3}{|l|}{ Slope } & \multicolumn{3}{|l|}{ Aspect } \\
\hline Value (m) & POT (\%) & POS (\%) & Value $\left(^{\circ}\right)$ & POT (\%) & POS (\%) & Value $\left(^{\circ}\right)$ & POT (\%) & POS $(\%)$ \\
\hline$<1000$ & 6.36 & 7.14 & 0 & 34.57 & 14.29 & 0 & 34.57 & 14.29 \\
\hline 1000-1300 & 27.93 & 50.00 & $0-5$ & 50.3 & 57.14 & $0-90$ & 18.53 & 21.43 \\
\hline $1300-1600$ & 42.33 & 21.43 & $5-10$ & 7.75 & 21.43 & $90-180$ & 13.75 & 42.86 \\
\hline 1600-1900 & 20.43 & 21.43 & $10-15$ & 4.00 & 7.14 & $180-270$ & 14.79 & 14.29 \\
\hline$>1900$ & 2.95 & 0 & $>15$ & 3.38 & 0 & $270-360$ & 18.36 & 7.14 \\
\hline Total & 100 & 100 & & 100 & 100 & & 100 & 100 \\
\hline
\end{tabular}

slope and aspect. It was difficult to quantify the contribution of slope and aspect on SAT variations from the model coefficients of $b_{3}, b_{4}$, and $b_{5}$, respectively. Therefore, partial regression analysis was used to identify the relative contribution of topographic factors to the SAT variations. A set of topographic factors were extracted in raster format to apply to the SAT models. The SAT maps were calculated using the model coefficients and raster layers in ArcGIS software.

\section{Evaluation of the interpolation and regression methods}

A total of 12 monthly SAT were mapped using the cokriging method in the Daqing Mountains. Figure 2 shows the mean SAT mapped from regression-based modeling (Fig. 2a) and co-kriging interpolation (Fig. 2b). Although the temperature gradient across the Daqing Mountains was captured by co-kriging interpolation, the spatial detail was obscured in the interpolated map presented in Fig. 2 b. Correspondingly, a few local temperature features stood out in Fig. 2a, such as the mountain peaks and Great Bend of the Yellow River (the Hetao Plain). Regional features on the regression-based map were also captured, such as the warmer area in the south and the cooler area in the north.

The mean MAE of SAT from the NTRSAT model was $0.67{ }^{\circ} \mathrm{C}$, with a range from 0.41 (September) to $1.08^{\circ} \mathrm{C}$ (February) (Fig. 3). The mean MAE of SAT from the cokriging method was $1.3{ }^{\circ} \mathrm{C}$, with a range from 1.1 (August) to $1.53{ }^{\circ} \mathrm{C}$ (March). The RMSE of SAT ranged from 0.31 to $0.74{ }^{\circ} \mathrm{C}$ in the NTRSAT model while it was from 0.42 to $0.91{ }^{\circ} \mathrm{C}$ in the co-kriging model. The MAE and RMSE values of co-kriging models were higher than those of regression models in all 12 months. The result indicated that the NTRSAT model works better than the co-kriging method in SAT modeling.

\section{Contributions of topographic factors}

Different regression models were compared based on $R^{2}$ values which represented the proportion of variation in the data explained by the model. As seen in Fig. 4, Model 1 had the lowest explanatory ability which accounted for an average of $80 \%$ of SAT variations. The $R^{2}$ of Model 1 changed significantly from 67.4 to $89 \%$ in different months. The mean $R^{2}$ value of Model 2 was $82.7 \%$, with a range from 72 to $91 \%$. By adding slope and aspect factors, Model 3 can account for an average of $88.7 \%$ of SAT variations, with a relatively small range from 84 to $93.4 \%$. In comparison with the linear models, the explanatory ability of NTRSAT (Model 4) increased noticeably, accounting for an average of $93.8 \%$ of SAT variations.

The $F$ values represented the relative contribution of topographic factors to SAT variations (Table 5). In the NTRSAT model, elevation had the strongest effect on SAT variations in 12 months. The mean contribution of elevation to SAT variations was $84.78 \%$ over 12 months. The mean contribution to SAT variations was $6.07 \%$ for latitude compared with $9.14 \%$ for the combined effect of slope and aspect. The relative contributions of latitude, slope, and aspect reached the maximum of $13.87 \%$ (latitude) and $18.9 \%$ (slope and aspect) in January.

\section{Discussion}

\section{Topographic effects and spatial scales}

Topographic effects on SAT variations depended on the spatial area of research region. In the macro-scale area, most studies only considered the effects of longitude and latitude on the SAT. Longitude and latitude determined the potential solar radiation and atmosphere circulation in the earth. The geographical location contributed most to the SAT variations (Daly et al. 1994, 2002). For example, longitude and latitude contributed to $58 \%$ of the total SAT variations in China (Fang 1992). In the meso-scale area, mountains served as temperature regulators for themselves and their surrounding areas. Large mountain massifs such as the Alps and Tibetan Plateau had a heating surface in summer by absorbing solar radiation and transforming it to long-wave energy. These so-called "mass elevation effects" led to higher air temperature compared to the surrounding atmosphere at same elevations. For example, 


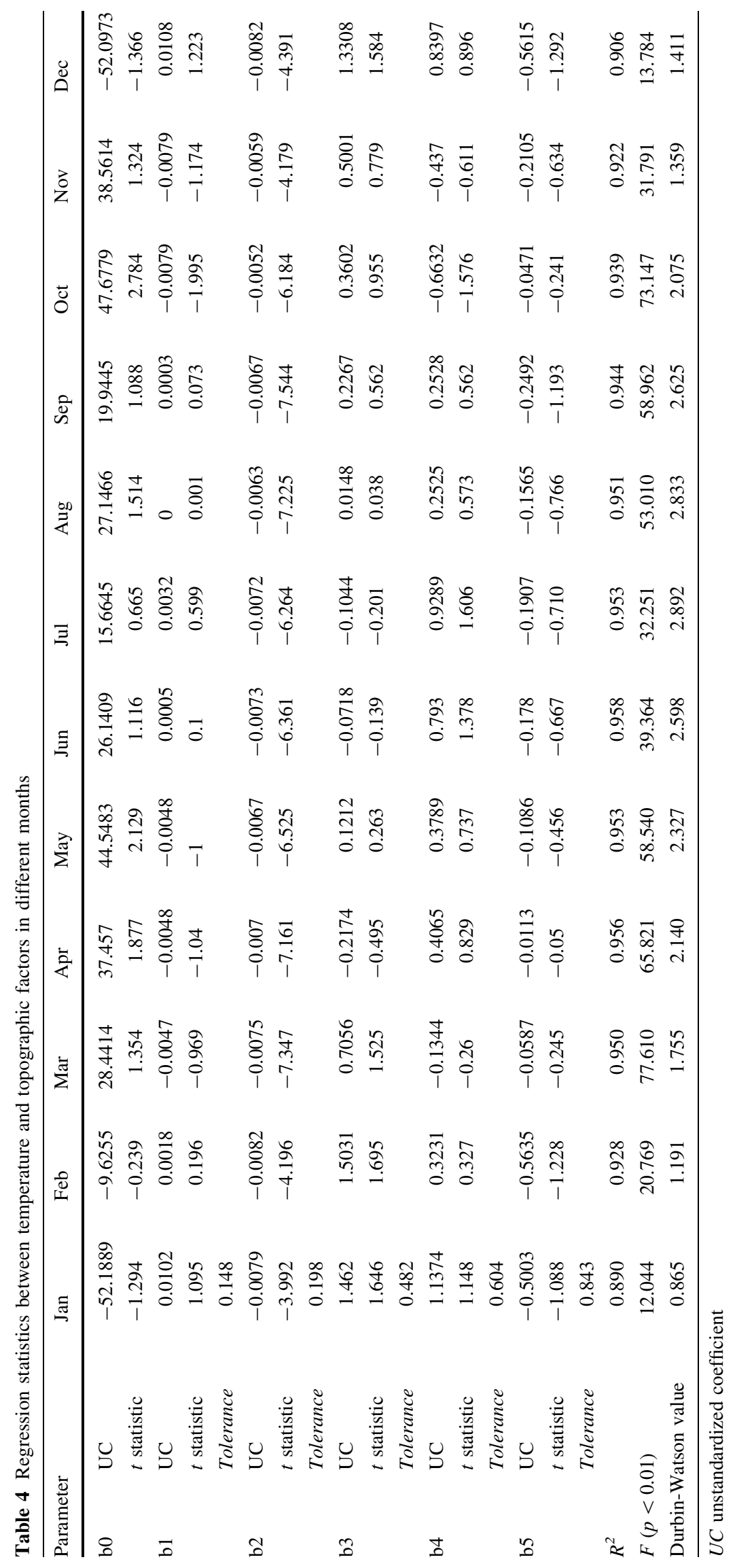



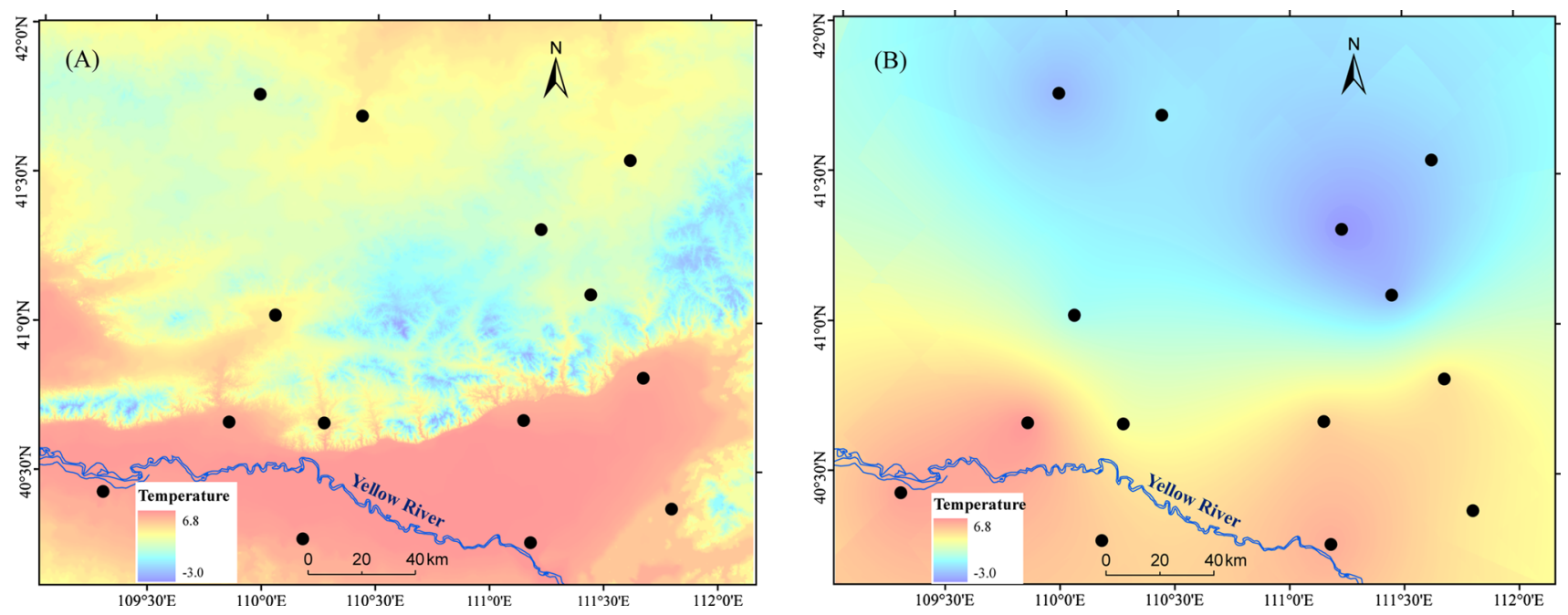

Fig. 2 Comparison of predicted temperatures between regression (a) and co-kriging methods (b)

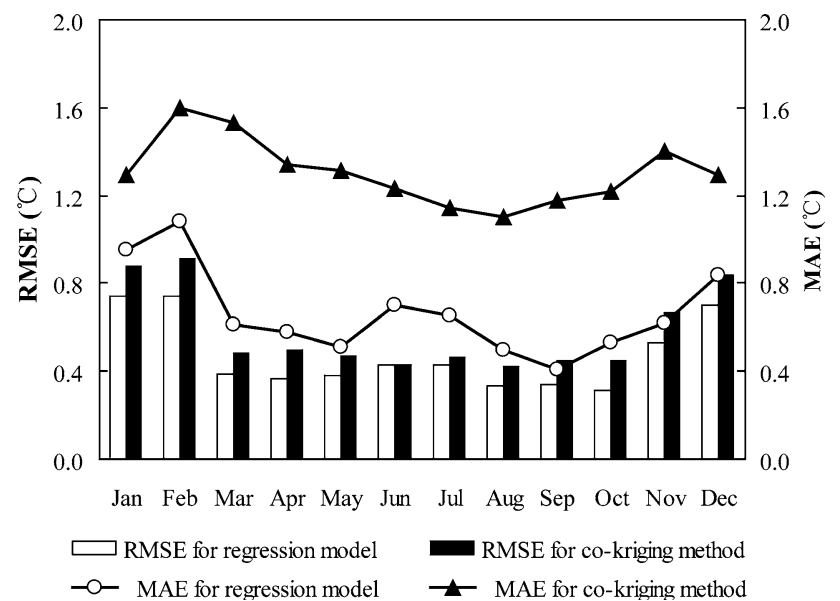

Fig. 3 Evaluation of temperature prediction from regression and cokriging methods. MAE is mean absolute error, and RMSE is root mean squared error

the monthly mean SAT in the interior Tibetan Plateau was approximately $2-7{ }^{\circ} \mathrm{C}$ higher than that in the surrounding mountains and adjacent lowland areas (Yao and Zhang 2014). Even in relatively small mountains, the temperature lapse rates can represent the elevation effect on the SAT. This study indicated that the SAT decreased with a temperature lapse rate of -5.2 (October) to $-8.2{ }^{\circ} \mathrm{C} \mathrm{km}^{-1}$ (February). Recent studies showed that the temperature lapse rates had a seasonal cycle which was due to the elevation-induced air-flow and inversion effect (Kattel et al. 2015). The surface solar radiation should be determined by the geographical location if the land surface is absolutely flat. However, the actual terrain was featured with complex slopes and aspects. In the local-scale area, complex terrain features affected direct, reflective, and diffuse components of solar radiation and lead to the

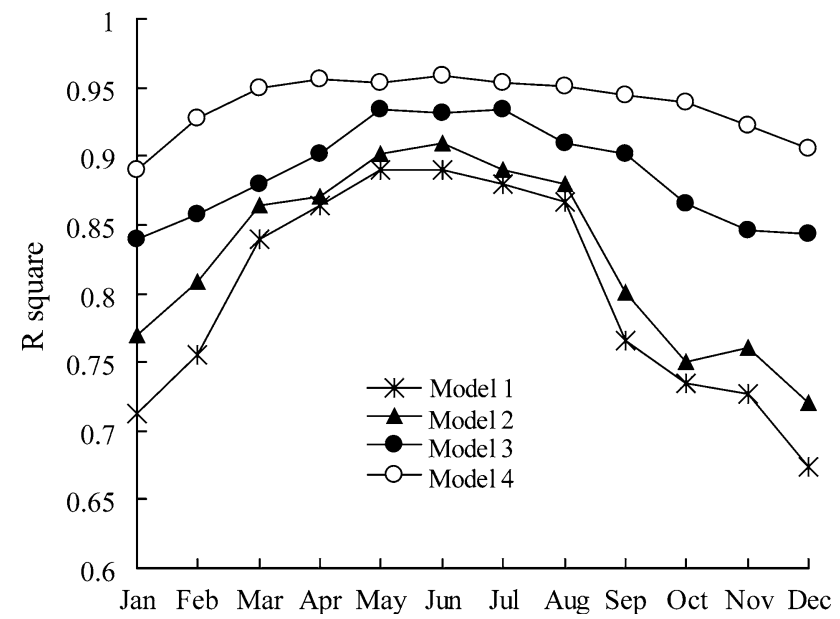

Fig. $4 R^{2}$ of regression models with different topographic factors included (Model 1: $T=b 0+b 2 H$; Model 3: $T=b 0+b 1 Y+b 2 H$; Model 3: $T=b 0+b 1 Y+b 2 H+b 3 \alpha+b 4 \beta ;$ Model 4: $T=b 0+b 1 Y+b 2 H+b 3 \cos \beta+b 4 \sin \beta \cos \alpha+b 5 \sin \beta \sin \alpha)$

redistribution of solar radiation in the earth's surface (Goodale et al. 1998). The local topographic features were innegligible factors for the SAT modeling (Zhang et al. 2002; Zhao et al. 2005; Liu and Zou 2006). Even slopes with same steepness may receive various solar radiation due to different aspects. Similarly, the same-degree aspect may have various solar radiation with different slope-degrees. Slope and aspect had a combined effect on the potential solar radiation according to the calculation equation (Kumar et al. 1997). The contribution of slope and aspect cannot be divided under this assumption. Partial regression analysis was an useful method to quantify the combined contribution of slope and aspect to SAT variations.

This study showed that the combined contribution of slope and aspect was larger than latitude in each month 
Table $5 \mathrm{~F}$ statistics and relative contributions (RC) of topographic factors in temperature regression

\begin{tabular}{|c|c|c|c|c|c|c|}
\hline \multirow[t]{2}{*}{ Month } & \multicolumn{2}{|c|}{ Latitude } & \multicolumn{2}{|c|}{ Elevation } & \multicolumn{2}{|c|}{ Slope and aspect } \\
\hline & $\mathrm{F}$ & $\mathrm{RC}(\%)$ & $\mathrm{F}$ & $\mathrm{RC}(\%)$ & $\mathrm{F}$ & $\mathrm{RC}(\%)$ \\
\hline Jan & $3.70 *$ & 13.87 & $17.93 * *$ & 67.23 & $5.04 * *$ & 18.90 \\
\hline Feb & 2.09 & 8.12 & $19.80 * *$ & 76.89 & $3.86^{*}$ & 14.99 \\
\hline Mar & $3.11 *$ & 4.53 & $60.70 * *$ & 88.51 & $4.77 * *$ & 6.96 \\
\hline Apr & 2.42 & 3.83 & $57.65 * *$ & 91.38 & $3.02 *$ & 4.79 \\
\hline May & 2.25 & 4.24 & $47.91 * *$ & 90.40 & $2.84 *$ & 5.36 \\
\hline Jun & 1.02 & 2.08 & $45.51 * *$ & 92.60 & 2.61 & 5.31 \\
\hline Jul & 1.81 & 3.77 & $44.15^{* *}$ & 92.04 & 2.01 & 4.19 \\
\hline Aug & 2.00 & 3.19 & $58.70 * *$ & 93.58 & 2.03 & 3.24 \\
\hline Sep & 2.02 & 2.89 & $64.05 * *$ & 91.53 & $3.91 *$ & 5.59 \\
\hline Oct & $3.68 *$ & 7.18 & $43.02 * *$ & 83.89 & $4.58 * *$ & 8.93 \\
\hline Nov & 2.01 & 7.76 & $19.65^{* *}$ & 75.90 & $4.23 * *$ & 16.34 \\
\hline Dec & $3.36^{*}$ & 11.40 & $21.68 * *$ & 73.46 & $4.47 * *$ & 15.15 \\
\hline
\end{tabular}

Significance at the level of $0.05(* *)$ and $0.1(*)$

(Table 5). This result indicated that the local topography (slope and aspect) had more impacts on the SAT variation than the latitude did. Some previous studies developed SAT models only using latitude, longitude, and elevation (Wang 1996; Bolstad et al. 1998; Goodale et al. 1998; Ninyerola et al. 2000); other studies added the effect of slope and aspect on SAT modeling (Brown and Comrie 2002; Xu et al. 2006). The slope and aspect were often considered as separate equation items for linear overlay with other topographic factors (Zhao et al. 2005; Liu and Zou 2006). They may also be used as the residual correction in spatial interpolation methods (Zhang et al. 2002). Most studies did not quantify the combined effect of slope and aspect from the meteorological processes. Therefore, the quantitative effect of slope and aspect could provide useful information for the SAT modeling in mountainous regions.

We also noted that the relative contribution of topographic factors was varied in different months. The average contribution of elevation was $77.6 \%$ from October to March less than $91.9 \%$ from April to September. Topographic factors at the macro-scale (latitude) and local-scale (slope and aspect) played more significant roles to capture SAT variations in winter than in summer. The differences in topographic effects might be due to the complex weather conditions, including strong Siberian High Pressure and intensified westerly winds (Liu et al. 2004), which may weaken or enhance the explanatory power of some topographic variables. This region had a steep slope in the southern side compared with the flat Inner Mongolia plateau in the northern side. The elevation contributed more impacts on the SAT variation in summer than in winter.

\section{Limitations and potential improvements}

Although the multivariate regression was a general method in predicting the SAT, this study indicated that the model accuracy can be improved by adding the effects of slope and aspect. The potential value of this study was the model structure not the model coefficients-because the model was fitted and tested in a specific mountain region.

The SAT models were constructed based on an assumption of potential solar radiation represented by the slope and aspect. Several factors might affect this assumption. For example, studies showed that snow cover could decrease the daily maximum and minimum SAT on average of 1.2 and $1.1{ }^{\circ} \mathrm{C}$, respectively. The maximum and minimum temperature depressions reached 4.5 and $2.6^{\circ} \mathrm{C}$ if snow depths were greater than $10 \mathrm{~cm}$ (Mote 2008). The vegetation cover and cloud could also affect the surface energy balance by reducing the amount of solar radiation (Hartmann et al. 1992; Holden et al. 2011). These factors could affect the accuracy of SAT models with topographic factors alone.

There may be other factors which were useful to SAT modeling. For example, mountain orientation was responsible for the SAT variation between the upward and leeward sides of mountains. Terrain curvature may be an alternative factor to detecting the cold air pooling and topographic depressions. However, these topographic effects should be quantified and verified in future research. Moreover, the influencing factors of SAT should be selected based on a tradeoff between model accuracy and efficiency. The selected factors should represent the stable effect on the SAT. This study indicated that four topographic factors can contribute to most of SAT variations (89-95.8\% of the spatial variation) in the Daqing Mountains. The simple and stable model structure facilitated its application in other regions.

In the study area, temperature stations had different elevations and may lie in different snow regimes. The lower stations may have snow cover less frequently whereas the ones at higher elevations have snow cover more frequently. The choice of temperature stations might be a factor impacting the explanation capability of regression models during the winter. We also noted the common feature of regression models for the over-fitted predicting wherein extremes in the data (Brown and Comrie 2002). The temperature stations can impact the resulting SAT prediction on steeper slopes and higher elevations. Our further analysis could be more meaningful if such data gaps were filled by collecting more and continuous land cover and cloud observations. These potential improvements opened some room for our further research. 


\section{Conclusions}

This study presented multivariate regression models to quantify the relative contribution of topographic factors to SAT variations. The nonlinear model only required the station data and topographic data. The results showed that elevation had the strongest effect on the SAT variation in all months, whereas the relative contribution of latitude, slope, and aspect increased in winter months. This study indicated that the regression model could be improved by quantifying topographic effects in different spatial scales. The simple and stable parameters of the model were main benefits for the SAT modeling and analysis in other complex mountain regions.

Acknowledgments The authors thank the anonymous reviewers for providing fruitful suggestions to improve the manuscript. The work was financed by the National Natural Science Foundation of China (41471150; 41030528).

\section{References}

Beek EG, Stein A, Janssen LLF (1992) Spatial variability and interpolation of daily precipitation amount. Stoch Hydrol Hydraul 6:304-320. doi:10.1007/BF01581451

Bolstad PV, Swift L, Collins F, Regniere J (1998) Measured and predicted air temperatures at basin to regional scales in the southern Appalachian mountains. Agric For Meteorol 91:161-176. doi:10.1016/S0168-1923(98)00076-8

Brown DP, Comrie AC (2002) Spatial modeling of winter temperature and precipitation in Arizona and New Mexico, USA. Clim Res 22:115-128. doi:10.3354/cr022115

Daly C, Neilson RP, Phillips DL (1994) A statistical topographic model for mapping climatological precipitation over mountainous terrain. J Appl Meteorol 33:140-158. doi:10.1175/15200450(1994)033<0140:ASTMFM >2.0.CO;2

Daly C, Gibson WP, Taylor GH, Johnson GL, Pasteris P (2002) A knowledge-based approach to the statistical mapping of climate. Clim Res 22:99-113. doi:10.3354/cr022099

Dodson R, Marks D (1997) Daily air temperature interpolated at high spatial resolution over a large mountainous region. Clim Res $8: 1-20$

Dozier J, Frew J (1990) Rapid calculation of terrain parameters for radiation modeling from digital elevation data. IEEE Trans Geosci Remote Sens 28:963-969. doi:10.1109/36.58986

Efron B (1982) The Jackknife, the Bootstrap and other resampling plans, vol 38. Society for Industrial and Applied Mathematics, Philadelphia, USA, pp 49-59. doi:10.1137/1.9781611970319.ch7

Fang JY (1992) Study on the geographic elements affecting temperature distribution in China. Acta Ecol Sin 12:92-104

Goodale CL, Aber JD, Ollinger SV (1998) Mapping monthly precipitation, temperature, and solar radiation for Ireland with polynomial regression and a digital elevation model. Clim Res 10:35-49

Hartmann DL, Maureen EO, Marc LM (1992) The effect of cloud type on Earth's energy balance: global analysis. J Clim 5:1281-1304. doi:10.1175/1520-0442(1992)005<1281: TEOCTO $>2.0 . \mathrm{CO} ; 2$

Holden ZA, Crimmins MA, Cushman SA, Littell JS (2011) Empirical modeling of spatial and temporal variation in warm season nocturnal air temperatures in two North Idaho mountain ranges, USA. Agric For Meteorol 151:261-269. doi:10.1016/j.agrfor met.2010.10.006

Huang SB (1986) Advance in the investigation of the topographical microclimate in China. Geographical Research 5:90-101

Kattel DB, Yao TD (2013) Recent temperature trends at mountain stations on the southern slope of the central Himalayas. J Earth Syst Sci 122:215-227. doi:10.1007/s12040-012-0257-8

Kattel DB, Yao TD, Yang W, Gao Y, Tian LD (2015) Comparison of temperature lapse rates from the northern to the southern slopes of the Himalayas. Int J Climatol. doi:10.1002/joc.4297

King ML (1981) The alternative Durbin-Watson test-An assessment of Durbin and Watson choice of test statistic. J Econom 17:51-66. doi:10.1016/0304-4076(81)90058-0

Kumar L, Skidmore AK, Knowles E (1997) Modelling topographic variation in solar radiation in a GIS environment. Int J Geogr Inf Sci 11:475-497

Lattin JM, Carroll JD, Green PE (2003) Analyzing multivariate data (in Chinese). China Machine Press, Beijing

Li HT, Shen WQ, Sang WG, Li JY (2001) Research situation and application of MTCLIM model. J Mt Sci 14:248-253

Liu PG (1992) The vertical distribution patterns of higher fungus and their evaluation from the Mt. Daqing. Inner Mongolia. Mt Res 10:19-24

Liu Y, Zou SB (2006) A study on the distributing climatic models in arid mountainous area-distributing temperature and precipitation models in high spatial resolution in the Qilian Mountains. J Lanzhou Univ 42:7-12

Liu CM, Qian ZA, Wu MC, Song MH, Liu JT (2004) A composite study of the synoptic differences between major and minor dust storm springs over the China-Mongolia areas. Terr Atmos Ocean Sci 15:999-1018

Lo YH, Blanco JA, Seely B, Welham C, Kimmins JP (2011) Generating reliable meteorological data in mountainous areas with scarce presence of weather records: the performance of MTCLIM in interior British Columbia, Canada. Environ Model Softw 26:644-657. doi:10.1016/j.envsoft.2010.11.005

Lookingbill TR, Urban DL (2003) Spatial estimation of air temperature differences for landscape-scale studies in montane environments. Agric For Meteorol 114:141-151. doi:10.1016/S01681923(02)00196-X

McKenney DW, Pedlar JH, Papadopol P, Hutchinson MF (2006) The development of 1901-2000 historical monthly climate models for Canada and the United States. Agric For Meteorol 138:69-81. doi:10.1016/j.agrformet.2006.03.012

Miao LJ, Jiang C, Xue BL, Liu Q, He B, Nath R, Cui XF (2015) Vegetation dynamics and factor analysis in arid and semi-arid Inner Mongolia. Environ Earth Sci 73:2343-2352. doi:10.1007/ s12665-014-3582-1

Mote TL (2008) On the role of snow cover in depressing air temperature. J Appl Meteorol Climatol 47:2008-2022. doi:10. 1175/2007JAMC1823.1

Ninyerola M, Pons X, Roure JM (2000) A methodological approach of climatological modelling of air temperature and precipitation through GIS techniques. Int J Climatol 20:1823-1841. doi:10. 1002/1097-0088(20001130)20:14<1823:AID-JOC566>3.0.CO; 2-B

Ollinger SV, Aber JD, Federer AC, Lovett GM, Ellis JM (1995) Modeling physical and chemical climate of the northeastern United States for a geographic information system. U.S. Forest Service General Technical Report NE-191, Radnor, PA, U.S. Department of Agriculture, p 30

Park S (2011) Integration of satellite-measured LST data into cokriging for temperature estimation on tropical and temperate islands. Int J Climatol 31:1653-1664. doi:10.1002/joc.2185 
Running SW, Nemani RR, Hungerford RD (1987) Extrapolation of synoptic meteorological data in mountainous terrain and its use for simulating forest evapotranspiration and photosynthesis. Can J For Res 17:472-483

Shao J, Tu D (1995) The Jackknife and Bootstrap. Springer-Verlag, New York

Sun RH, Zhang BP, Tan J (2008) A multivariate regression model for precipitation estimation in the Daqing Mountains. Mt Res Dev 28:318-325. doi:10.1659/mrd.0944

Sun RH, Chen LD, Fu BJ (2011) Predicting monthly precipitation with multivariate regression methods using geographic and topographic information. Phys Geogr 32:269-285. doi:10.2747/ 0272-3646.32.3.269

Tao S, Fu C, Zeng Z, Zhang Q, Kaiser D (1991) Two long-term instrumental climatic data bases of the People's Republic of China. Oak Ridge, TN, USA: Oak Ridge National Laboratory ORNL/CDIAC-47

Wallace J, Corr D, Kanaroglou P (2010) Topographic and spatial impacts of temperature inversions on air quality using mobile air pollution surveys. Sci Total Environ 408:5086-5096. doi:10. 1016/j.scitotenv.2010.06.020

Wang L (1996) The temperature calculation model for the mountainous areas in North China and its application. J Nat Res 11:150-156

Weng DM, Luo XZ (1990) Mountain climate (In Chinese). China Meteorological Press, Beijing

$\mathrm{Xu} \mathrm{XT,} \mathrm{Xie} \mathrm{YW,} \mathrm{Ma} \mathrm{JH} \mathrm{(2006)} \mathrm{Modeling} \mathrm{of} \mathrm{temperature} \mathrm{and}$ precipitation distribution in Xinglong Mountain area. Remote Sens Technol Appl 21:317-321

Yao YH, Zhang BP (2014) The mass elevation effect of the Tibetan Plateau and its implications for Alpine treelines. Int J Climatol Publ Online. doi:10.1002/joc.4123

Zhang HL, Ni SX, Deng ZW, Chen Y, Zha Y (2002) A method of spatial simulating of temperature based digital elevation model (DEM) in mountain area. J Mt Sci 20:360-364

Zhao CY, Nan ZR, Cheng GD (2005) Methods for modeling of temporal and spatial distribution of air temperature at landscape scale in the southern Qilian Mountains, China. Ecol Model 189:209-220. doi:10.1016/j.ecolmodel.2005.03.016 